\title{
Provider, Heal Thy System: An Examination of Institutionally Racist Healthcare Regulatory Practices and Structures
}

\author{
Kelly M. Roberts ${ }^{1}$ (D) Andrea N. Trejo ${ }^{2}$ \\ Accepted: 14 December 2021 / Published online: 28 January 2022 \\ (c) The Author(s), under exclusive licence to Springer Science+Business Media, LLC, part of Springer Nature 2021
}

\begin{abstract}
U.S. history is fraught with examples of systemic racism-at all ecological levels and within all geopolitical contexts. Whether scholars historically punctuate these phenomena through white racial framing begun in the 1600s or the Black civil rights movement of the 1960s, research across disciplines brings into focus a twenty-generation story of injustice. These phenomena present a paradoxical struggle within healthcare systems populated by professionals who have made a "conscious commitment to equity and helping those in need." However, both healthcare systems and embedded care providers operate in relation to organizational structures that frequently reify racist policies. As natural and professional agents of change, medical family therapists are especially positioned to examine how regulatory systems at every level influence institutional racism within the medical and mental health fields. In this manuscript we examine health system policies and practices using the lens of C.J. Peek's Four Worlds: Clinical, Operational, Financial, and Training. Examples of institutional racism are discussed and recommendations for approaches to change are provided.
\end{abstract}

Keywords Healthcare $\cdot$ Institutional racism $\cdot$ Medical family therapy $\cdot$ Healthcare policy

“...Marriage and family therapists are defined by an enduring dedication to professional and ethical excellence, as well as the commitment to service, advocacy, and public participation. The areas of service, advocacy, and public participation are recognized as responsibilities to the profession equal in importance to all other aspects..." (American Association for Marriage and Family Therapy [AAMFT], 2015).

\section{Defining the Problem}

A paradox exists within U.S. healthcare systems and, by virtue of their systemic membership, medical family therapists (MedFT) themselves. Each time research reveals evidence of modern-day institutional racism, the troubling findings stand in direct contradiction to healthcare professionals' core

Kelly M. Roberts

kelly.roberts@oc.edu

Andrea N. Trejo

AndreaNTrejo@uga.edu

1 Oklahoma Christian University, Edmond, OK, USA

2 University of Georgia, Athens, USA mission and conscious commitment to equity when helping those in need (AAFP, 2019; Elias \& Paradies, 2021; Geiger, 2006). Yet despite reviews of hundreds of studies across diseases illustrating the breadth and depth of racist practices or policies in healthcare (Geiger, 2006; Institute of Medicine, 2003; Sohler \& Bromet, 2003), professionals are reluctant to believe that their own behaviors and the policies of their institutions may be negating their professional oaths and principles (Geiger, 2006; Institute of Medicine, 2003).

Solutions like medical education programs on cultural humility or health equity have more addressed the persons than the policies of healthcare. And bodies of work assigned during clinical practitioners' training programs address frameworks and specific approaches for competencies at the individual level (Hansen \& Metzi, 2019). As professionals sworn to a mission, healthcare providers frequently research themselves, committed to do better and be more respectfulattempting to identify and eradicate any remnants of racism or implicit biases that may still exist in the corners of their minds or conditioned responses (Ufomata et al., 2021). The majority of research investigating institutional racism within healthcare seems to bear that out by the high volume focus on feedback surveys related to the interactions of patients and providers or "visit service quality" (Nong et al., 2020; Williams et al., 2019; Paradies et al., 2014). However, a 
professional is who they are in relation to the system within which they practice, and America's institutionally racist story exists on a vast and weighty scale.

U.S. healthcare historians have authenticated profound and horrific examples of situational and longitudinal racism at all ecological levels and within all geopolitical contexts (Feagin \& Bennefield, 2013; Griffith et al., 2007). Past health care atrocities include documented eugenics, surgeries without anesthesia, and evidence of how researchers subjected Black people to torture by withholding treatment for syphilis (Feagin \& Bennefield, 2013). Many social justice scholars punctuate these phenomena through the white racial framing begun in the $1600 \mathrm{~s}$ during the development of the New England colonized territories, or the Black civil rights movement of the 1960s (Feagin, 2020; Lane, 2017). Regardless of the reference point, however, racial inequity scholarship brings into focus a twenty-generation story of injustice. ${ }^{1}$

Recent studies have shown that modern-day communities of color, especially Black, Latinx, and Native American communities, continue to receive lower quality healthcare (Cullen et al., 2020; Gillispie-Bell, 2021; Martyr et al., 2019). These experience are intermingled with other psychological, behavioral or phenomenological sequelae such as: (1) pervasive racial and ethnic disparities, (2) inaptitudes with "weathering" or historical trauma, and (3) functional discrimination in power heirarchies not exclusive to individual level race and ethnicity but also inherently present within modern medical systems (Banks, 2020; Findling et al., 2019; Geronimus et al., 2006; Griffeth et al., 2007; Sotero, 2006; Wingfield \& Chavez, 2020; Woodger \& Cowan, 2011).

In fact, structural and institutional research questions only recently began more rapidly rising to the top of white public and academic queues, gaining loft from the voices of Black Lives Matter (BLM) and eliciting a robust investment of advocacy not previously seen. It is important to acknowledge, however, that researchers of color have been raising these questions for decades, but white stakeholders were not receptive-a form of racial gaslighting (Davis \& Earnst, 2017). BLM's collective call for seeing ourselves, in relation to the institutions wherein we reside and practice is clarion, coming from a broad meta-level that no doubt provided traction for new thinking. Bailey et al. (2021) offer a rich examination of this 5-year priority shift influenced by BLM in their recent work published in the New England Journal of Medicine; they end their work with this charge:

Organized medicine and public health have a long history of opposing desegregation and broader access to care (e.g., Medicare), of barring Black physicians, of

\footnotetext{
${ }^{1}$ We have chosen to align our choice of utilizing a lowercase white in solidarity with the positions of multiple institutions discussed by the Brookings Institute's David Lanham on July 16, 2020.
}

championing scientific racism, and of enshrining race as a biologic variable. Our fields have much to regret, and we have much still to offer to right our historical wrongs. Let's not sit on the sidelines. (p. 771)

As natural and professional agents of change with refined systemic analysis skills, MedFTs are especially positioned to examine the institutions within their worlds of work and steer clear of "the sidelines." MedFT exemplifies a history of publications addressing racism and disparities (Hodgson et al., 2018; Rajaei \& Jensen, 2019; Willerton et al., 2008). Our goal is to add to MedFT's body of work by utilizing C.J. Peek's Four Worlds [Clinical, Operational, Financial (2008), and Training (2019)] as a framework to examine current examples of institutional racism, or propose areas of inquiry, within: (1) policies and practices of diagnostic criteria (Clinical); (2) professional organizations (Operational); (3) federal agencies and reimbursement systems (Financial); and, (4) accrediting agencies (Training). Each of these areas go hand-in-hand with the overarching biopsychosocialspiritual (BPSS) approach to patient treatment, marrying an institutional/professional, systemic assessment of the secondary and tertiary healthcare levels and the impacts they have on the primary patient/provider levels. Post-analysis recommendations will be offered for further change along with suggested priorities.

\section{Analysis of Healthcare-Affiliated Institutions}

\section{Medical Diagnosing and the Implications for Treatment (Clinical)}

The harmful impacts of racism on physical and mental health are well documented (e.g., Anderson, 2013; McKenzie, 2003; Trent et al., 2019). However, the intersection between mental health and racism, as well as the best way to address this intersection in the Diagnostic Statistical Manual of Mental Disorders (DSM-5), has been a source of controversy. In earlier editions of the DSM, some scholars advocated for the inclusion of "the perpetration of racism" as a mental disorder (Thomas, 2014), but received backlash by other scholars and editors who asserted that in doing so, they would add to the myth that systems perpetuating racism both institutionally and individually are exceptional or outliers, rather than omnipresent (Okoro, 2005; Thomas, 2014). Others asserted these types of revisions would continue to implicate white supremacy as the primary and foundational institution of cause but would do nothing for the individuals harmed by it (Thomas, 2014). In recent years, the focus of revisions and scholarly input has shifted to the inclusion of mechanisms to demonstrate, or account for, the effects of racism when clinically working with communities of color. 
In some cases, the lack of acknowledgement in the DSM-5 can actually prevent fuller and more accurate conceptualizations and research detailing just how harmful racism can be. For example, some scholars have called attention to the diagnostic criteria for Post-Traumatic Stress Disorder in particular (Willliams et al., 2018). The diagnostic criteria currently limits qualifying events to events in which an individual has directly experienced or witnessed threat to their or someone else's life (APA, 2013). Criterion A and its four descriptors ("exposure to actual or threatened death, serious injury, or sexual violence"; APA, 2013) currently fails to account for the cumulative, chronic, intergenerational threat and harm of living in a white supremacist world. Additionally, given the increased access to video streaming and social media, communities of color are constantly witnessing violence toward their community at the hands of authorities, government, and civilians. This is not meant to imply that this witnessing does not occur outside of social media, but rather that social media has increased access to the witnessing of these events (Bryant-Davis et al., 2017; Campbell \& Valera, 2020; Hawkins, 2021; Staggers-Hakim, 2016). Although Criterion A descriptors do account for indirect exposure to details of a traumatic event in the course of professional work (APA, 2013), they do not account for the effects of indirect exposure to these events via media. This blunts clinicians' understanding of post-traumatic stress due to white supremacist harm (also referred to as race-based or ethno-racial trauma; Williams et al., 2018), and directly impacts access to appropriate treatments for communities of color. We acknowledge that persons of color may feel impacted to greater or lesser degrees within these examples. For example, many people of color have noted that the knowledge and witnessing of the aforementioned violence, albeit painful, is nothing new (Campbell \& Valera, 2020). However, these impacts are also ignored through the lack of acknowledgement of the effects of racism within the DSM-5.

Calls have also been made for the creation of International Classification of Diseases (ICD-10) codes that track hate crimes and social determinants of health (Jacobs, 2021; Samuels, 2017). Implementing this classification of codes would be important for two reasons. A code or way of accounting for stress and/or harm due to racism and white supremacy would more accurately contextualize any resulting mental health struggles, and therefore more precisely inform treatment plans and interventions for healing. This would also be a way to move away from pathologizing the mental health effects of living in a racist, white supremacist society, and place the onus of harm onto the society itself.

While DSM-5 and ICD-10 codes will always be incomplete in capturing the human experience, these codes serve important roles in American healthcare as it is currently designed. Health policy professionals depend upon accurate data collection as the first step to affecting institutional, policy-based change. The addition of more specific, categorical codes could be a step in accurately identifying individuals whose physical and mental health complaints are a direct result of, or at least exacerbated by, ethno-racial trauma or stress, and/or other social determinants of health, and to track the incidence of health symptoms related to race-based violence and racism. Although this step may seem rudimentary, this type of data would be invaluable in the development of antiracist mental health, research, policy change, and government funding. With additional codes, the conceptual push for removing blame and responsibility from patients of color and onto the societal systems causing harm (e.g., the medical and mental healthcare systems) would also be reflected in documentation.

System-based DSM-5 and ICD-10 codes are not lacking (Jacobs, 2021); some examples include "exposure to disaster, war, and other hostilities" (V62.22/Z65.5), "lack of adequate food or safe drinking water" (V60.2/Z59.4), "inadequate housing" (V60.1/Z59.1), "unavailability or inaccessibility of health care facilities (V63.9/Z75.3), "unspecified problem related to social environment" (V62.9/Z60.9), and "victim of crime/ victim of torture" (V62.89/Z65.4) (APA, 2013). Given the extensive list of options to capture systemic barriers to health and thriving, the absence of codes capturing experiencing a hate crime or inadequate housing due to racism and redlining is even more disturbing. To exhaust this point, "acculturation difficulty" (V62.4/Z60.3; APA, 2013) is available, but not "inadequate resettlement resources due to xenophobia" or "barred access to asylum/ protected citizenship."

Accurate documentation would hopefully be one step in shifting closer to addressing root causes of pain, instead of only managing symptoms. MedFTs witness the effects of institutional racism on a daily basis; enhancing their tools by adding appropriate codes to accurately describe racial harms could increase clinical impacts. Without tools to accurately diagnose, BPS-S treatment approaches are incomplete. However, well-described small steps toward capturing the root of many Americans' mental health struggles (racism and white supremacy) can grow into pathways of health equity.

\section{Professional Organizations (Operational)}

On November 16th, 2020, the American Medical Association declared racism a public threat (AMA, 2020). Around this same time, other professional organizations like the American Association of Marriage and Family Therapy (AAMFT) and the American Psychiatric Association (APA) put out statements denouncing racism, and announcing priorities to begin diversity, equity, and/or inclusion initiatives alongside recommendations for antiracist training and healthcare provision (AAMFT, 2020; APA, 2020). In December of 2020, The National Council on Family 
Relations (NCFR) put out a statement about George Floyd and announced a "call to action" from their Board of Directors. This was followed in 2021 with a statement over the teaching of Critical Race Theory (CRT) and then followed by a statement to members who were being targeted with harmful social media and direct email rhetoric based upon that release (L. Leslie, N. Burgess \& D. Cushman, personal communication. November 1, 2021). The Collaborative Family Healthcare Association (CFHA) dedicated their entire 2021 conference to the theme of "Justice, Health Equity, and Reducing the Digital Divide." In addition, a web-page banner dedicated to "Black Lives Matter" takes the visitor to a resource page on relevant topics including "how to talk to Black clients about racial trauma and Black lives lost" (CFHA, 2021). The following text is from the AAMFT statement, offered as just one example of the multiple professional organizational responses released over the past 2 years:

Because we value how systems impact families and communities, AAMFT is outraged by the continued racial trauma, violence, and loss that our communities of color are experiencing in this country. (...) Our members, our clients, and our society are hurting deeply and we must stand together and in solidarity against injustice. There is no room in our society for inequality and it is vital that we use our platform, relationships, and training to enact change. It is a core value in AAMFT to support, promote, and protect diversity, to value all individuals and groups as free from prejudice and oppression as possible, and to foster a climate where equity and mutual respect are intrinsic. Marriage and family therapists have a direct responsibility to counter racism. We are uniquely positioned to understand and recognize the systemic effect that oppression, inequity, and overt and covert racism have on individuals in marginalized communities and have a role in fostering healing and growth. Therefore, AAMFT stands in support of our members dedicated to advancing the fundamental rights, health, safety, and well-being of all individuals, relationships, and communities. We encourage all members to have authentic dialogue to advance systemic change. As an organization, we will continue to advocate against societal inequalities and seek solutions in our clinical, research, community, and policy work to ensure that vital change is occurring. (AAMFT, 2020)

Standing against racism as an organization in 2020, albeit essential, was too little too late. Organizations must reflect on their institutionally racist roots and actions, perform self-examination exercises with diverse groups of their own members or race equity consultants, and acknowledge their historical role in perpetuating and profiting from racism. On
October 29, 2021, the American Psychological Association (APA) issued a sobering apology "to people of color for APA's role in promoting, perpetuating, and failing to challenge racism, racial discrimination, human hierarchy" in the United States (APA, 2021). This apology seemed to finally capture what so many initial statements tiptoed around: organizations' own complicitness and quiet protection of white supremacist medical and mental healthcare.

Stating a position as a large body of professionals can serve as a powerful tool to crystalize views of acceptable and aspirational behaviors, demonstrating a strong first step. But these statements must not remain static; there is still room for more growth to build upon the initial work. The historical path to the date of authorship on these statements represents such a lengthy journey that cannot and should not be conveniently erased. Efforts must continue to evolve from these statements, producing further products and artifacts of change. Ideas for these introspective and externally reaching steps are only limited by those involved in creating them,

but redistributing power and prioritizing communities of color must be the focus. Building initiatives to grow organizational leadership and memberships that reflect the U.S. population is important but the white supremacist influences on all structural components within an organization must be actively audited, acknowledged, and wrestled with. All aspects of organizational development should be examined, including the academy and connection to training. This period of reflective examination could be followed by creating concrete and tangible plans to dismantle quieter policies and professional rules of conduct that encourage these academic environments to sustain ingrained practices-environments that prioritize protecting white founding scholars and leaders of a field, over doing the work to transform the full culture of their organization (Bell et al., 2021). If an environment of racial inequity was the impetus for so many statements from so many professional organizations, then surely the statements can be evidence that there is still work to be done within our own organizational halls and governing bodies.

\section{Accrediting Agencies (Operational/Financial)}

Although there are a variety of accrediting bodies across the healthcare sector, agencies commonly referred to as "the Big Five" have a pervasive reach and require a large number of resources dedicated to meeting and maintaining their standards (Mumford, et al., 2015): the Commission on Accreditation of Rehabilitation Facilities (CARF); the Council on Accreditation (COA); the National Committee for Quality Assurance (NCQA); The Joint Commission (TJC); and, the Utilization Review Accreditation Commission (URAC). Many employment positions and even departments within healthcare systems exist as a direct result of 
maintaining accreditation compliance. Literature abounds on the pros and cons of accrediting bodies, frequently drawing distinctions between the increased patient safety and lowered risks versus a problematic "teaching to the test" culture that can, at its worst, amount to a focus on "gaming the system" (Viswanathan \& Salmon, 2000).

Regardless of debates on their merits, healthcare accrediting agencies have a powerful sway in how they influence or could potentially influence change. Fundamentally the Big Five's core mission is a commitment to quality, accountability and patient safety, and at certain levels, managing costs and data stewardship. But beyond those fundamental standards, TJC has more recently released affirmatively-framed guidance documents over the topics of racism and health equity in healthcare, suggested educational resources over these topics, and published calls for leadership to prioritize the eradication of racism-linking the importance of these initiatives with the overall quality level of service delivery (TJC, 2016-2021). Additionally, TJC released an organizational statement on "Racial Justice and Equity" and hired a Chief Diversity and Inclusion Officer (TJC, 2021). Several accrediting bodies, as well as institutions across the country, took steps to release similar statements in or around the year 2020. The COA seemed to take their own organizational statement on racism a bit further by publishing "guiding principles" that:

...specifically examine the extent to which they decrease racial disparities and oppression, particularly in systems and settings known to disproportionately and negatively impact people of color and other marginalized groups; advance solutions that have been developed in collaboration with and have the support of impacted communities; incorporate an intersectional and multi-sector approach to community challenges; and include the investments needed to fully implement and achieve racial equity outcomes. (COA, 2020)

It is a natural fit of accrediting bodies' mission to serve as resource centers for healthcare systems seeking to address institutionally embedded racism. However, a review of materials published across accrediting bodies seem to have an outward-bound flow: most publications are calls from accreditors to healthcare organizations to do better. Based upon these calls for action, we met with four large-system PoC healthcare leaders who had also served in national federal HHS positions or led healthcare policy commissions on a national level. Those discussions were conducted to get a sense of the leaders' responses to these calls for action. All declined to be identified yet agreed to the sentiment that one quote offered during those discussions: "Accrediting bodies ten states removed from my community are telling $m e$ about how to eradicate racism? I'd be more impressed if they examined themselves and then told me what they found (personal communications, December 2020, January 2021 \& March, 2021)."

Similar to the developmental stage of the professional organizations' public statements shared earlier, accrediting bodies have influential institutional positions to lead by taking further, action-oriented steps-building upon their own calls for action from systems they accredit to include actions for themselves.

\section{Federal Agencies (Financial)}

While acknowledging the largess of possible institutionally racist phenomena across federal healthcare policies, this section will focus on federal financial policies covering the costs of healthcare for First Americans (first humans to settle the Americas, ancestors of today's Native Americans) as a case example. The United States has a federal trust responsibility to provide services, including healthcare, to First Americans (Warne \& Frizzell, 2014). Despite this codified responsibility, decades-long issues remain rigidly problematic and serve as an exercise in institutional failings. Areas discussed include: (1) disparities in per capita funding; and, (2) the state-based organizational structures governing.

\section{Medicaid Funding for Tribes}

\section{Disparities in Per Capita Funding}

To understand the complexities of funding for Indian Health Service (IHS), it is important to first acknowledge that budgets for the IHS are reviewed by several Congressional committees or bodies including the House and Senate Committees on Appropriations. Additionally, IHS leadership and various tribal leaders and national tribal organizations provide annual testimony to the House Committee on Appropriations, Subcommittee on Interior, Environment and Related Agencies; and the Senate Committee on Indian Affairs is also involved (IHS, 2021). Yet, despite the multiple ears and eyes involved in this annual process, the per capita spending for the IHS has remained lower than other agency counterparts:

According to a December 2018 report from the federal watchdog Government Accountability Office, in 2017 the IHS spent $\$ 4078$ per beneficiary compared with $\$ 8109$ for Medicaid, $\$ 10,692$ for the VA and $\$ 13,185$ for Medicare. "In each of the four programs, the per capita spending was relatively stable from 2013 through 2017," according to the GAO. [King, 2019 (See Fig. 1)]

Recently, the Biden administration moved to shrink this per capita problem by proposing an increase in IHS spending 
Fig. 1 Per capita spending per patient, 2018 government accountability office data (King, 2019)

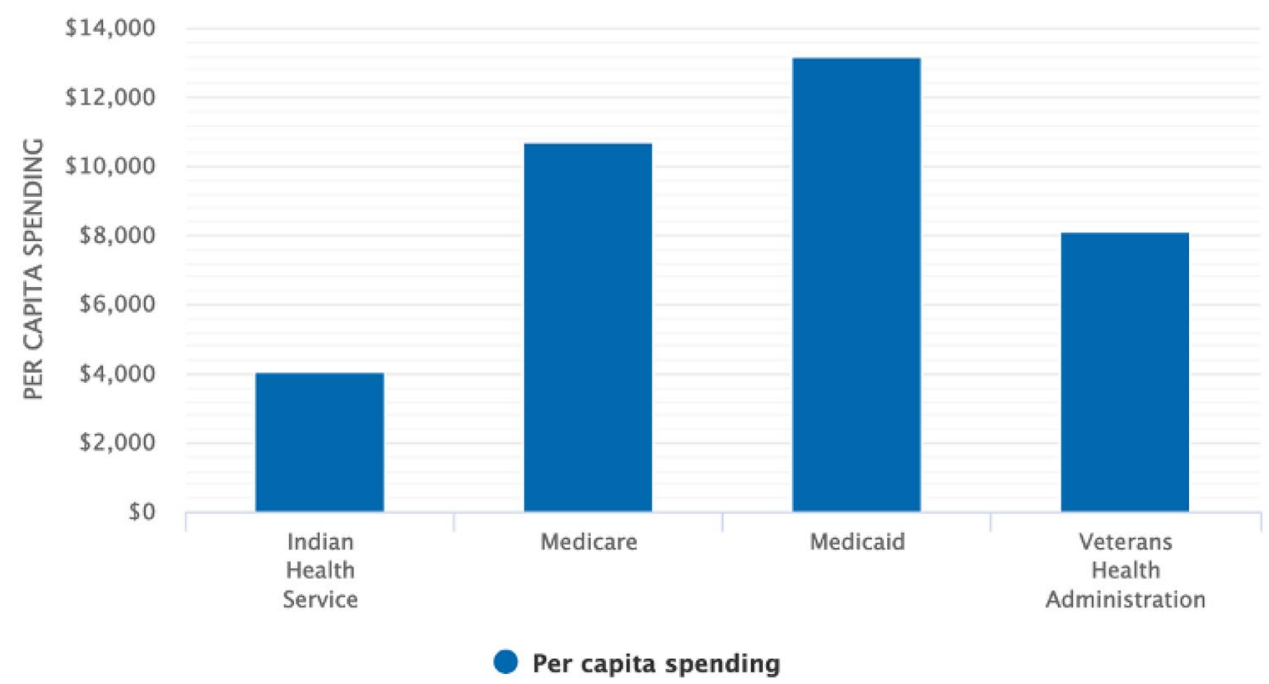

by $17 \%$ (Rickert, 2021). If funded at face value, this change will narrow the gap significantly, but not close it. Healthcare administrators will also be dealing with "catching up" for years, due to having lowered the priority for facilities maintenance, or dealt with workforce challenges since facilities opened their doors. Whether any changes take place remains to be seen as the budget moves through the approval processes.

\section{State-Based Medicaid Administration}

The U.S. Centers for Medicaid and Medicare Services (CMS) provides oversight for state Medicaid plans filed on an annual, or even ongoing, basis. Tribes located within 41 of the 50 states are required to use those specific state plans to administer approved healthcare services at their locations, even though the status of their Medicaid dollars are federal "pass through," not a federal-state share. This situation becomes especially problematic because there are two main challenges tribes must deal with due to federal trust responsibilities not being fully recognized. First, they operate by a "pass through" mechanism for their funds. Tribes bill the state Medicaid administrative agency with which they are affiliated, and the money is marked as "pass through," meaning the agency takes the federal money and passes it to the tribes based upon their billing data. However, the state agencies are provided an administrative fee for this process, averaging around ten percent. This means that even though Medicaid dollars specifically allocated for tribes are simply passed on to the tribes, the tribes have to absorb an administrative fee rather than realize that funding for their own uses (see: 100\% FMAP, CMS, 2021). Tribes have frequently proposed to CMS that a "fifty-first state" be created in order to serve as the administrative body for dollars to be forwarded directly but attempting to find workable solutions for 574 federally recognized tribes in a single policy has been more than challenging. If this problem were acknowledged in the beginning, agency rules and structures as well as federal direct payments to tribes would have been normalized. Now, the problem is gargantuan with no solution in sight.

A secondary problem related to both institutional equity problems and racism is that state Medicaid administrators also get paid for the number of people they serve, including persons who are tribal members being served in IHS/Tribal facilities. In the Medicaid calculus for each state, tribal members (ranging from approximately $2-10 \%$ depending upon the state) are included as the general population census. Therefore, although tribes and IHS facilities may bear the cost of providing healthcare services to their members, albeit at a lower per capita rate, it is the state CMS administrator that receives generalized formula funding for these persons in their areas-not the tribes. Therefore, states are paid to administer direct federal funding and are paid for tribal members even though they are served by federally partnered IHS or Tribal facilities. Awareness of these issues is not new, but the ability to get them changed thus far has been non-existent.

\section{Effects on Other Systematically Oppressed Groups}

While this section was framed with specific examples related to federal agencies and First American populations, documented institutional inflexibility most certainly includes other people of color. Two resources are notable for understanding ongoing contextual racial healthcare issues with Medicaid as the catalyst for examination. Greene et al. (2006) examined physician characteristics and Medicaid program variables; their analysis showed that physicians' choices not to serve persons of color by avoiding racially diverse geographic residential areas creates disparities, 
thus reifying institutionally racist practices. Although circumstantial, their work appeared to show that patient race influences access to physicians. And, a narrative of "How Foundational Moments in Medicaid's History Reinforced Rather Than Eliminated Racial Health Disparities" was contributed to the "Health Affairs" blog (Nolan et al., 2020). The story of structural/institutional racism evolution within the Medicaid system unfolded from the 1960s through the Covid-19 pandemic; pivotal moments within this blog post can be extrapolated and overlaid with other evidence provided within this manuscript.

\section{MFT/MedFT Training Programs (Training)}

The lack of racial and ethnic diversity in Marriage and Family Therapy, and by virtue of that discipline, the lexicon and theories of Medical Family Therapy, is not a recent or new concern. Mental health scholars and professionals have long called attention to the need for a diverse and culturally responsive workforce (e.g., Bocanegra et al., 2015; Bocanegra et al., 2016; Brunson et al., 2010; Lebensohn-Chialvo et al., 2021; Peters et al., 2014; Weng \& Gray, 2017). These calls to action focus on addressing admissions requirements, incorporating social justice into coursework and program missions, recruiting more diverse students and faculty, and reducing the financial burden of pursuing a mental health graduate degree (Bocanegra et al., 2015, 2016; Peters et al., 2014; Weng \& Gray, 2017). These calls to action are notable and should be heeded; however, recruitment and retention initiatives risk falling flat if we fail to pay attention to the insidious ways in which white supremacy shapes MFT/ MedFT as a field, and thus, seeps into our programs' departments, curricula, and climates. Both must occur in order to create the changes we seek.

\section{Origins of MFT and MedFT}

In a recent article, “'Why Aren't There Any MFT Programs at Historically Black Colleges or Universities?': Expanding the Reach of MFT Education and Training," featured in the AAMFT's Family Therapy Magazine, Dr. Leslie Anderson (2020) calls attention to several sobering realities. All 128 COAMFTE-accredited MFT programs in the United States and Canada are situated in historically white institutions (Anderson, 2020). According to COAMFTE's most recent report, $71 \%$ of faculty and $69 \%$ of supervisors identify as non-Latinx white individuals, compared to constituting approximately $60 \%$ of the U.S. population (Anderson, 2020; COAMFTE, 2020; Ghosh, 2020). These statistics, while disappointing, are hardly surprising. Rather, they are evidence of a harmful and problematic legacy.

American mental healthcare was born out of a need to uphold the power and superiority of white Americans. One of the original aims of early American psychiatry was to provide "scientific" support for the enslavement of Black individuals (Maultsby, 1982). For example, Samuel Cartwright, a white physician and enslaver, invented and popularized two fictional mental health disorders in the 1850s: drapetomania, "the insanity that caused slaves to run away," and dysaesthesia aethioptica, "the mental disease that caused slaves to try to avoid work, to destroy their masters' property, and generally to irritate their overseers" (Maultsby, 1982, p. 42). We fast forward to the 1930s, when Paul Popenoe, a California-based eugenicist, establishes the first marriage counseling clinic in the U.S., the American Institute of Family Relations (Ladd-Taylor, 2001). Popenoe believed that marriage counseling, as well as eugenic sterilization, could be a powerful tool in protecting the institution of marriage, preventing divorce, and encouraging procreation in the "fit," while preventing the "unfit" (read systematically oppressed individuals and individuals struggling with mental illness) from marrying and having children (Ladd-Taylor, 2001). Popenoe received an honorary Sc.D. from Occidental College for his work; this honorary degree was not rescinded until 2019 (Ladd-Taylor, 2001). Popenoe's problematic work has been conveniently erased from MFT history. In Michael P. Nichol's (2017a, b) seminal textbook, Family Therapy: Concepts and Methods (11th Edition), there is no mention of the context surrounding Popenoe's influence on the field:

The first centers for marriage counseling were established in the 1930s. Paul Popenoe opened the American Institute of Family Relations in Los Angeles, and Abraham and Hannah Stone opened a similar clinic in New York. (p. 12)

We now turn to MFT's (white) founding fathers and pioneers. While their theoretic contributions gain much attention in MFT training programs, the historic backdrop of the Civil Rights Movement is not often discussed. For example, Bateson et al. (1956) influential report "Toward a Theory of Schizophrenia" was published in 1956, only a year after Rosa Parks famously refused to give up her bus seat to a white person in Montgomery, Alabama, leading to her arrest and the Montgomery Bus Boycott. Jay Haley, Murray Bowen, Nathan Ackerman, and Carl Whitaker's most significant contributions also spanned the 50-60 s. However, the absence of this context from their work is palpable, and reflective of the field's persistent avoidance of naming and discussing the role of white supremacy in MFT.

To further this point, we can consider the following passage in Nichols' (2017a, b) text on addressing cultural differences in therapy:

In working with minority families, it may be more important for therapists to develop cultural sensitivity than to actually share the same background as their 
clients. Families may come to trust a therapist who has taken the time to learn about their particular culture as much as one who happens to be of the same race or nationality. One way to develop cultural sensitivity is to make connections after working hours. For example, a white therapist could attend an African American church service in the community where his or her clients live, go to a Latino dance, or visit an Asian community center. Doing these things won't make you an expert, but it may demonstrate to client families that you care enough to respect their ways. (p. 39)

In addition to the racial stereotypes utilized in this passage, is the troubling absence of a deeper conversation about the need for therapists-especially white therapists-to understand their own complicitness with white supremacy, their own racist beliefs and biases, and their own problematic behaviors before engaging with clients. Furthermore, white therapists working with clients of color must be aware of the privileges and power they hold, and of the systemic issues affecting communities of color due to white supremacy. If we are to move towards true racial equity in mental healthcare, only training providers to be culturally sensitive and respectful towards communities to which they do not belong, is not, and never will be, enough. Addressing this training deficit will require both a systemic assessment of policies that shape cultural responsiveness training across MFT and within individual institutions, and institutional protection of faculty who push for this deeper level of reflection, particularly if it falls onto faculty of color, as diversity efforts often do (Balzora, 2021; Trejo, 2020).

\section{Development and Accreditation of COAMFTE programs}

MFT and MedFT program development is largely shaped by COAMFTE accreditation standards and state-level licensing requirements. The COAMFTE accreditation process is lengthy (COAMFTE, 2019). MFT and MedFT programs use COAMFTE guidelines and accreditation standards to form their curriculum. COAMFTE has also shaped MFT licensure (Lyness, 2020). The COAMFTE guiding principles specifically refer to instilling cultural competency in trainees in three of the seven guiding principles for Version 12 Accreditation Standards (COAMFTE, 2019):

Guiding Principle \#1: Programs must prepare professionals for the variety of roles they fulfill in the community and reflect the contemporary professional climate.

Guiding Principle \#3: Inherent in the relational/systemic perspective is the importance of always considering context and recognizing the value of multiple perspectives; MFTs are multiculturally-informed and consider a global context.
Guiding Principle \#4: Programs must strive for diversity and inclusion (p. 3).

Attention to these principles is measured through a variety of methods, including self-narratives on the program's commitment to diversity and inclusion, as well as program strategies for recruiting and retaining diverse students, evaluating the program climate and fostering a safe one, and providing students with experiences around providing MFT services to diverse and underserved populations (COAMFTE, 2019). The effectiveness of COAMFTE's attempts to regulate programs' adherence to a commitment to diversity and inclusion initiatives is unclear. MFT students and therapists of color have reported inadequate training and problematic program climates for several years, including experiences of being oppressed by faculty (e.g., Artavia-Turckel, 2017; Erolin \& Wieling, 2021; McDowell et al., 2012; Mittal \& Wieling, 2006; Wilson \& Stith, 1993). This discrepancy between standards and practice is cause for concern. Are program faculty reliable informants regarding program climate and diversity initiatives?

It is worth noting that COAMFTE does conduct site visits, during which site visitors should "conduct meetings with students and graduates of the program" and "review formal student complaints and grievances" (COAMFTE, 2019, p. 19). This step is often conducted years into the accreditation process. And although it is comforting to know that COAMFTE values student feedback, it is less clear how much time is given for students to voice concerns, and whether programs reliably inform students that they have this opportunity during these evaluations. This also assumes that students feel safe voicing concerns in a formal way. However, it may be more likely that students who have experienced harm from faculty, especially racism and other forms of discrimination or harassment, will not have the support, security or power to disclose their experiences, let alone receive reparations.

Given that previously mentioned calls for more diversity in the field (e.g., McDowell et al., 2002; Wilson \& Stith, 1993) are over two decades old, we must consider whether MFT programs, which exist in white supremacist academic systems, and are primarily taught by white faculty (COAMFTE, 2020), are capable of regulating and overseeing their own efforts in supporting diverse faculty and trainees, creating safe and socially just learning and working environments, and preparing trainees to serve marginalized communities. Furthermore, are COAMFTE commissioners, all of whom are white, or at least white passing, as of July 2021 (COAMFTE, n.d.), capable of deciding what successful attainment of these goals looks like? The language of "striving for diversity and inclusion," in and of itself, implies a passivity towards that goal, embedded in the myth that, by reaching out to a handful of students of color, or by hoping 
for more diverse applicants, we are actively working towards a more diverse student population. When these efforts fail to erase centuries of violent history, exclusion, and gatekeeping, we engage in racial gaslighting, blaming students of color for not applying to or choosing our programs. The reality is that working with diverse individuals has always been treated as an add-on skillset. For example, only three states, Arizona, Connecticut, and New Jersey, currently require Continuing Education Units (CEUs) in some sort of cultural competency training for MFT licensure renewal (AMFTRB, n.d.). Until we truly begin to embrace cultural responsiveness and antiracism as core skills for all faculty, first, and trainees, second, we will continue to drive away students of color. Furthermore, we will continue to fail clients of color until we begin to treat cultural responsiveness and antiracism training, and the transformation of our existing workforce and programs, as an ethical obligation.

\section{Summary and Call for Action}

Tackling the topic of "institutional racism in healthcare" within a single publication is an impossible task for a scholar of any professional discipline. But for MedFTs, whose "areas of service, advocacy, and public participation are recognized as responsibilities to the profession equal in importance to all other aspects," the call to begin, or continue, is clear (American Association for Marriage and Family Therapy, 2015). The call to prioritize should now be clarion. The goal of this manuscript was to contribute to MedFT's body of work by utilizing C.J. Peek's Four Worlds [Clinical, Operational, Financial (2008), and Training (2019)] as a framework for examining current examples of institutional racism and shedding light on areas of inequity. Our hope is that this examination illuminated policybased, institutionally reinforced areas of racism in need of honorable, full-throated advocacy to affect meaningful and long-lasting differences. And while this examination was not exhaustive, it is our hope the discussion has provided a spark of inertia to light the beginning of your own inquiry within your own healthcare systems. Based upon evidence of current and persistent racism presented, we offer the following recommendations to the field of MedFT, including medical family therapists across the globe who might have similar histories to face:

(1) Provider, heal thy profession first. Develop a systematic approach to shed light on the furthest corners and darkest crevices of institutional racism in our training institutions, our own research labs, and our professional organizations. We must place an emphasis foremost on examining and re-examining where we should target change so that the souls and voices of our profession reflect the souls and voices we serve. Given the opportunity and their specific training related to medical systems, MedFTs should truly excel at this area and could easily serve as leads during the process.

(2) Heal thy healthcare systems simultaneously. The work of ensuring safe, inclusive, respectful and healing systems must be of equal importance. The professional and ethical call of MedFTs exists because of the patient. Finding ways to begin the work of changing our healthcare contexts, therefore, can only be a "both-and" proposition. Because the field of medical family therapy is slightly younger than other professions, the maturity of this profession within larger healthcare systems may not be yet realized. Healthcare systems can tend toward hierarchical and tend to award long-term professionals. However, most all accredited healthcare systems work toward continued accreditation which requires committee work. And, with well-respected frameworks such as "Health in All Policies (National Center for Health Statistics, 2016)," what MedFTs lack in professional longevity, they make up for in ingenuity and system applications of ideas.

(3) And then, heal thy local, state, federal, tribal, and other government systems. When professionals are clear-eyed in their mission, they are most ready to effect change within the chaotic world of legislative and government bodies. The important work of advocacy for lasting change with the goal of eradicating institutional racism in healthcare must come, if only slightly behind, the goal of healing ourselves. As the field of MedFT continues to populate healthcare systems across the nation and world, ensuring that MedFTs are equipped to carry advocacy and policy-development as a part of their skill set can lead to broader and more lasting changes toward eradicating institutional racism.

Feagin and Bennefield (2013) remind us that while some would say change on the institutional level is too difficult, evidence of these types of meta-level changes are happening in Canada, some European countries and within the National Institutes of Health. While their comments were distilled, they mention that "shifting health care framing and structuring to accent well-run nationalized health care has positive systemic impacts. Countries with nationalized systems not so linked to race and class usually have less health inequality than the U.S. (p. 12)".

Communicating our profession's own changes back to researchers of institutional racism is an important element in boosting trajectories, momentum, and speed of change. Institutions tend to respond to institutions, and just as the statements regarding racism were quick to be publicized, results of self-examinations can rapidly spread. Depending upon how historians punctuate or memorialize 
societal tipping points, acknowledgements of the Black Civil Rights movement of the 1950s and 60 s should soon be seeing seventy-fifth anniversary commemorations. We suggest MedFTs be ready for announcements, large and small, to respond to M.L. King's famous words about how "darkness cannot drive out darkness" with a focused, bright, and systemic light.

\section{References}

American Academy of Family Physicians (2019). Institutional Racism in the Healthcare System. Retrieved July, 2019, from https:// www.aafp.org/about/policies/all/institutional-racism.html

American Association for Marriage and Family Therapy (AAMFT). (2015). 2015 Code of Ethics. https://www.aamft.org/Legal_Ethics/Code_of_Ethics.aspx

American Association for Marriage and Family Therapy (AAMFT). (2020). AAMFT statement on MFT responsibility to counter racism. Retrieved June, 2020, from https://blog.aamft.org/2020/06/ aamft-statement-on-mft-responsibility-to-counter-racism.html

American Medical Association (AMA). (2020). New AMA policy recognizes racism as a public health threat. Retrieved November, 2020, from https://www.ama-assn.org/press-center/press-relea ses/new-ama-policy-recognizes-racism-public-health-threat

American Psychiatric Association (APA). (2013). Diagnostic and statistical manual of mental disorders (5th ed.). American Psychiatric Association.

American Psychiatric Association (APA). (2020). APA presidential task force to address structural racism throughout psychiatry begins its work. Retrieved July, 2020, from https:// www.psychiatry.org/newsroom/news-releases/apa-presidenti al-task-force-to-address-structural-racism-throughout-psych iatry-begins-its-work

American Psychological Association (APA). (2021). Apology to people of color for APA's role in promoting, perpetuating, and failing to challenge racism, racial discrimination, and human hierarchy in U.S. Retrieved October 29, 2021, from https://www.apa.org/about/ policy/racism-apology

Anderson, K. F. (2013). Diagnosing discrimination: Stress from perceived racism and the mental and physical health effects. Sociological Inquiry, 83(1), 55-81. https://doi.org/10.1111/j.1475682X.2012.00433.x

Anderson, L. (2020, August). "Why aren't there any MFT programs at historically Black colleges or universities?": Expanding the reach of MFT education and training. MFT Education and Therapists of Color, pp 16-19

Artavia-Turckel, I. V. (2017). Understanding the experiences of Latino students in MFT graduate programs (Publication No. 10601660). [Doctoral dissertation, Alliant International University]. ProQuest Dissertations Publishing

Association of Marital and Family Therapy Regulatory Boards (AMFTRB). (n.d.). AMFTRB state continuing competency chart. Accessed 30 Nov 2021. https://amftrb.org/resources/continuingcompetency-chart/

Bailey, Z. D., Feldman, J. M., \& Bassett, M. T. (2021). How structural racism works-Racist policies as a root cause of the U.S. racial health inequities. New England Journal of Medicine, 384, 768-773. https://doi.org/10.1056/NEJMms2025396

Balzora, S. (2021). When the minority tax is doubled: Being Black and female in academic medicine. Nature Reviews
Gastroenterology \& Hepatology, 18(1), 1-1. https://doi.org/10. 1038/s41575-020-00369-2

Banks, B. (2020). Addressing racism in healthcare: A case study (Publication No. 28153407). [Doctoral dissertation, University of Minnesota]. ProQuest Dissertations Publishing

Bateson, G., Jackson, D. D., Haley, J., \& Weakland, J. (1956). Toward a theory of schizophrenia. Behavioral Science, 1(4), 251-264.

Bell, M. P., Berry, D., Leopold, J., \& Nkomo, S. (2021). Making Black Lives Matter in academia: A black feminist call for collective action against anti-blackness in the academy. Gender, Work \& Organization, 28, 39-57. https://doi.org/10.1111/gwao.12555

Bocanegra, J., Gubi, A., Fan, C., \& Hansmann, P. (2015). Undergraduate psychology students' knowledge and exposure to school psychology: Suggestions for diversifying the field. Contemporary School Psychology, 19(1), 12-20. https://doi.org/10.1007/ s40688-015-0046-x

Bocanegra, J., Newell, M., \& Gubi, A. (2016). Racial/ethnic minority undergraduate psychology majors' perceptions about school psychology: Implications for minority recruitment. Contemporary School Psychology, 20(3), 270-281. https://doi.org/10.1007/ s40688-016-0086-X

Brunson, W. D., Jackson, D. L., Sinkford, J. C., \& Valachovic, R. W. (2010). Components of effective outreach and recruitment programs for underrepresented minority and low-income dental students. Journal of Dental Education, 74(supplement 10), S74-S86. https://doi.org/10.1002/j.0022-0337.2010.74.10_suppl.tb04984.x

Bryant-Davis, T., Adams, T., Alejandre, A., \& Gray, A. A. (2017). The trauma lens of police violence against racial and ethnic minorities. Journal of Social Issues, 73(4), 852-871. https://doi.org/10. 1111/josi.12251

Campbell, F., \& Valera, P. (2020). "The only thing new is the cameras": A study of US college students' perceptions of police violence on social media. Journal of Black Studies, 51(7), 654-670. https:// doi.org/10.1177/0021934720935600

Centers for Medicare and Medicaid (CMS) (2021). 100\% FMAP for LTSS-Educate Your State. Retrieved December 1, 2021, from https://www.cms.gov/Outreach-and-Education/American-IndianAlaska-Native/AIAN/LTSS-TA-Center/info/100-percent-fmapeducate-your-state

Collaborative Family Healthcare Association. (2021). Anti-racism. Retrieved November 12, 2021, from https://integratedcareconsul tation.com/resources/anti-racism/

Commission on Accreditation for Marriage and Family Therapy Education (COAMFTE). (2019). Accreditation manual: Policies and procedures. Retrieved November, 2019, from https://www.coamf te.org/documents/COAMFTE/COAMFTE\%20Accreditation\% 20Manual $\% 20$ Policies\%20and\%20Procedures.pdf

Commission on Accreditation for Marriage and Family Therapy Education (COAMFTE). (2020). Aggregated program demographic data. Accessed 30 Nov 2021. https://www.coamfte.org/COAMF TE/COAMFTE/Directory_of_Accredited_Programs/Program_ Demographic_Data.aspx

Commission on Accreditation for Marriage and Family Therapy Education (COAMFTE). (n.d.). Meet the commissioners. https://www. coamfte.org/COAMFTE/About_COAMFTE/Meet_the_Commi ssioners.aspx

Cullen, T., Demaree, M., \& Effler, S. (2020). Closing the health disparity gap for American Indians and Alaska Natives through health IT modernization. Health Affairs Blog. https://doi.org/10.1377/ hblog20200122.299286

Davis, A. M., \& Ernst, R. (2017). Racial gaslighting. Politics, Groups, and Identities. https://doi.org/10.1080/21565503.2017.1403934

Elias, A., \& Paradies, Y. (2021). The costs of institutional racism and its ethical implications for healthcare. Bioethical Inquiry, 18, 45-58. https://doi.org/10.1007/s11673-020-10073-0 
Erolin, K. S., \& Wieling, E. (2021). The experiences of couple/marriage and family therapists of color: A survey analysis. Journal of Marital and Family Therapy, 47(1), 3-20. https://doi.org/10. 1111/jmft.12456

Feagin, J. (2020). The white racial frame: Centuries of racial framing and counter-framing ( $3 \mathrm{rd}$ ed.). Routledge.

Feagin, J., \& Bennefield, Z. (2013). Systemic racism and U.S. healthcare. Social Science and Medicine, 103, 7-14. https://doi.org/10. 1016/j.socscimed.2013.09.006

Findling, M. G., Casey, L. S., Frybert, S. A., Hafner, S., Blendon, R. J., Benson, J. M., Sayde, J. M., \& Miller, C. (2019). Discrimination in the United States: Experiences of Native Americans. Health Services Research, 54(52), 1431-1441. https://doi.org/10.1111/ 1475-6773.13224

Geiger, H. J. (2006). Health disparities: What do we know? What do we need to know? What should we do? In A. J. Schulz \& L. Mullings (Eds.), Gender, race, class, \& health: Intersectional approaches (pp. 261-288). Jossey-Bass/Wiley.

Geronimus, A. T., Hicken, M., Keene, D., \& Bound, J. (2006). "Weathering" and age patterns of allostatic load scores among Blacks and Whites in the United States. American Journal of Public Health, 96(5), 826-833. https://doi.org/10.2105/AJPH.2004.060749

Ghosh, I. (2020). Visualizing the U.S. population by race. Visual capitalist. Retrieved December, 2020, from https://www.visualcapi talist.com/visualizing-u-s-population-by-race/

Gillispie-Bell, V. (2021). The contrast of color: Why the Black community continues to suffer healthcare disparities. Obstetrics and Gynecology, 137(2), 220-224. https://doi.org/10.1097/AOG. 0000000000004226

Greene, J., Blustein, J., \& Weitzman, B. (2006). Race, segregation, and physicians' participation in medicaid. The Milbank Quarterly, 84, 239-272. https://doi.org/10.1111/j.1468-0009.2006.00447.x

Griffith, D. M., Mason, M., Yonas, M., Eng, E., Jeffries, V., Plihcik, S., \& Parks, B. (2007). Dismantling institutional racism: Theory and action. American Journal of Community Psychology, 39, 381-392. https://doi.org/10.1007/s10464-007-9117-0

Hansen, H., \& Metzl, J. M. (2019). Structural competency in mental health and medicine. Springer International Publishing.

Hawkins, D. S. (2021). "After Philando, I had to take a sick day to recover": Psychological distress, trauma and police brutality in the Black community. Health Communication. https://doi.org/10. 1080/10410236.2021.1913838

Hodgson, J., Lamson, A., Aamar, R., \& Limon, F. (2018). Medical family therapy in community health centers. In T. Mendenhall, A. Lamson, J. Hodgson, \& M. Baird (Eds.), Clinical methods in medical family therapy Focused issues in family therapy. Springer.

Indian Health Service (IHS). (2021). Congressional committees. Retrieved November 1, 2021, from https://www.ihs.gov/clao/ congressionalcommittees/

Institute of Medicine (US). (2003). Committee on understanding and eliminating racial and ethnic disparities in health care. In B. D. Smedley, A. Y. Stith, \& A. R. Nelson (Eds.), Unequal treatment: Confronting racial and ethnic disparities in health care. National Academies Press (US).

Jacobs, Z. G. (2021). Codifying social determinants of health: A gap in the ICD-10-CM. Journal of General Internal Medicine, 36, 3205-3207. https://doi.org/10.1007/s11606-021-06742-4

King, R. (2019). Indian health service swept up in efforts to boost transparency. Retrieved March 16, 2019, from https://www.moder nhealthcare.com/providers/indian-health-service-swept-up-effor ts-boost-transparency-oppose-medicare-all

Ladd-Taylor, M. (2001). Eugenics, sterilization and modern marriage in the USA: The strange career of Paul Popenoe. Gender \& History, 13(2), 298-327. https://doi.org/10.1111/1468-0424.00230

Lane, K. (2017). Giving up the microphone: The white racial framing of race. [Master's thesis, University of North Alabama]. CORE.
UNA Scholarly Repository. Accessed 30 Nov 2021. https://core. ac.uk/download/pdf/198424014.pdf

Lebensohn-Chialvo, F., Kalafut, M. J., Hernandez, S. F., \& Trejo, A. N. (2021). Recruiting and training multilingual family therapists: A content analysis of COAMFTE-accredited marriage and family therapy program websites. Journal of Marital and Family Therapy. https://doi.org/10.1111/jmft.12497

Lyness, K. P. (2020). Training and credentialing in the profession of marriage and family therapy. In K. S. Wampler, R. B. Miller, \& R. B. Seedall (Eds.), The handbook of systemic family therapy (pp. 555-575). Wiley.

Martyr, M., Kivlighan, D. M., \& Ali, S. R. (2019). The role of telepsychology training clinics in addressing health disparities with rural Latinx immigrant communities. Translational Issues in Psychological Science, 5(4), 346-354. https://doi.org/10.1037/tps00 00208

Maultsby, M. C. (1982). A historical view of Blacks' distrust of psychiatry. In S. M. Turner \& R. T. Jones (Eds.), Behavior modification in Black populations (pp. 39-55). Springer.

McDowell, T., Fang, S. R., Brownlee, K., Young, C. G., \& Khanna, A. (2002). Transforming an MFT program: A model for enhancing diversity. Journal of Marital and Family Therapy, 28(2), 179-191. https://doi.org/10.1111/j.1752-0606.2002.tb00355.x

McDowell, T., Fang, S. R., Kosutic, I., \& Griggs, J. (2012). Centering the voices of international students in family studies and family therapy graduate programs. Journal of Marital and Family Therapy, 38(s1), 332-347. https://doi.org/10.1111/j.1752-0606. 2012.00310.x

McKenzie, K. (2003). Racism and health: Antiracism is an important health issue. BMJ, 326(7380), 65-66. https://doi.org/10.1136/bmj. 326.7380 .65

Mittal, M., \& Wieling, E. (2006). Training experiences of international doctoral students in marriage and family therapy. Journal of Marital and Family Therapy, 32(3), 369-383. https://doi.org/10.1111/j. 1752-0606.2006.tb01613.x

Mumford, V., Greenfield, D., Hogden, A., Forde, K., Westbrook, J., \& Braithwaite, J. (2015). Counting the costs of accreditation in acute care: An activity-based costing approach. British Medical Journal Open, 5(9), e008850. https://doi.org/10.1136/bmjop en-2015-008850

National Center for Health Statistics. (2016). Health, United States, 2015: With special features on racial and ethnic health disparities. Hyatsville: National Center for Health Statistics (US). Retrieved May, 2016, from https://www.cdc.gov/nchs/data/hus/ hus15.pdf

Nichols, M. P. (2017a). The evolution of family therapy. In M. P. Nichols \& S. D. Davis (Eds.), Family therapy: Concepts \& methods (11th ed., pp. 8-26). Pearson.

Nichols, M. P. (2017b). Basic techniques of family therapy: From symptom to system. In M. P. Nichols \& S. D. Davis (Eds.), Family therapy: Concepts \& methods (11th ed., pp. 27-49). Pearson.

Nolan, L. T., Beckman, A. L., \& Sandoe, E. (2020). How foundational moments in medicaid's history reinforced rather than eliminated racial disparities. Health Affairs Blog. https://doi.org/10.1377/ hblog20200828.661111/full/

Nong, P., Raj, M., Creary, M., Kardia, S. L. R., \& Platt, J. E. (2020). Patient-reported experiences of discrimination in the U.S. health care system. Journal of the American Medical Association Network Open, 3(12), e2029650. https://doi.org/10.1001/jamanetwor kopen.2020.29650

Okoro, D. C. (2005). Racism and mental disorders. Psychiatric Services, 56(2), 220-220. https://doi.org/10.1176/appi.ps.56.2.220

Paradies, Y., Truong, M., \& Priest, N. (2014). A systematic review of the extent and measurement of healthcare provider racism. Journal of General Internal Medicine, 29(2), 364-387. https://doi.org/ 10.1007/s11606-013-2583-1 
Peters, M. L., Sawyer, C. B., Guzmán, M. R., \& Graziani, C. (2014). Supporting the development of Latino bilingual behavioral health professionals. Journal of Hispanic Higher Education, 13(1), 15-31. https://doi.org/10.1177/1538192713514611

Rajaei, A., \& Jensen, J. F. (2019). Empowering patients in integrated behavioral health-care settings: A narrative approach to medical family therapy. The Family Journal, 28, 48-55.

Rickert, L. (2021). President Joe Biden issues five new initiatives at the White House tribal Nations summit. Native news online. Retrieved November 15, 2021, from https://nativenewsonline. net/currents/president-joe-biden-issues-five-new-initiatives-atthe-white-house-tribal-nations-summit

Samuels, E. A. (2017). Diversity matters: No ICD-10 code for hate crimes. Emergency Medicine News. https://doi.org/10.1097/01. EEM.0000513573.06597.54

Sohler, N. L., \& Bromet, E. J. (2003). Does racial bias influence psychiatric diagnoses assigned at first hospitalization? Social Psychiatry and Psychiatric Epidemiology, 38(8), 463-472.

Sotero, M. M. (2006). A conceptual model of historical trauma: Implications for public health and practice. Journal of Health Disparities Research and Practice, 1, 93-108.

Staggers-Hakim, R. (2016). The nation's unprotected children and the ghost of Mike Brown, or the impact of national police killings on the health and social development of African American boys. Journal of Human Behavior in the Social Environment, 26(3-4), 390-399. https://doi.org/10.1080/10911359.2015.1132864

Thomas, J. M. (2014). Medicalizing racism. Contexts, 13(4), 24-29. https://doi.org/10.1177/1536504214558213

The Joint Commission. (2021). Take 5: The Joint Commission's New Inclusion and Diversity Activities. Retrieved December 1, 2021, from https://www.jointcommission.org/resources/news-and-multi media/podcasts/take-5-the-joint-commissions-new-diversity-andinclusion-activities/

Trejo, J. (2020). The burden of service for faculty of color to achieve diversity and inclusion: The minority tax. Molecular Biology of the Cell, 31(25), 2752-2754. https://doi.org/10.1091/mbc. E20-08-0567

Trent, M., Dooley, D. G., \& Dougé, J. (2019). The impact of racism on child and adolescent health. Pediatrics. https://doi.org/10.1542/ peds.2019-1765

Ufomata, E., Merriam, S., Puri, A., Lupton, K., LeFrancois, D., Jones, D., Nemith, A., Snydman, L., Stark, R., \& Spagnoletti, C. (2021). A policy statement of the society of general internal medicine on tackling racism in medical education: Reflections on the past and a call to action for the future. Journal of General Internal Medicine, 36(4), 1077-1081. https://doi.org/10.1007/s11606-020-06445-2

Viswanathan, H. N., \& Salmon, J. W. (2000). Accrediting organizations and quality improvement. The American Journal of Managed Care, 6(10), 1117-1130.

Warne, D., \& Frizzell, L. B. (2014). American Indian health policy: Historical trends and contemporary issues. American Journal of Public Health, 104(Suppl 3), 263-S267. https://doi.org/10.2105/ AJPH.2013.301682

Weng, S. S., \& Gray, L. A. (2017). Advancement in social work education: Fostering a supportive environment for students of nondominant racial and ethnic backgrounds. Social Work Education, 36(6), 662-677. https://doi.org/10.1080/02615479.2017.1335700

Willerton, E., Dankoski, M. E., \& Martir, J. F. S. (2008). Medical family therapy: A model for addressing mental health disparities among Latinos. Families, Systems, \& Health, 26(2), 196-206. https://doi.org/10.1037/1091-7527.26.2.196

Williams, D., Lawrence, J., \& Davis, B. (2019). Racism and health: Evidence and needed research. Annual Review of Public Health, 40, 105-125. https://doi.org/10.1146/annurev-publh ealth-040218-043750

Williams, M. T., Metzger, I. W., Leins, C., \& DeLapp, C. (2018). Assessing racial trauma within a DSM-5 framework: The UConn racial/ethnic stress \& trauma survey. Practice Innovations, 3(4), 242. https://doi.org/10.1037/pri0000076

Wilson, L. L., \& Stith, S. M. (1993). The voices of African-American MFT students: Suggestions for improving recruitment and retention. Journal of Marital and Family Therapy, 19(1), 17-30. https://doi.org/10.1111/j.1752-0606.1993.tb00962.x

Wingfield, A. J., \& Chavez, K. (2020). Getting in, getting hired, getting sideways looks: Organizational hierarchy and perceptions of racial discrimination. American Sociological Review, 85(1), 31-57. https://doi.org/10.1177/0003122419894335

Woodger, D., \& Cowan, J. (2011). Institutional racism in healthcare services: Using mainstream methods to develop a practical approach. Ethnicity and Inequalities in Health and Social Care, 3, 36-44. https://doi.org/10.5042/eihsc.2011.0076

Publisher's Note Springer Nature remains neutral with regard to jurisdictional claims in published maps and institutional affiliations. 